Mesut Polat • Yusuf Yildirim - A. Seckin Onoglu

\title{
Visual analog scale pain score after laparoscopic tubal sterilization: comparison of micro-laparoscopy and conventional technique
}

Published online: 18 November 2005

(C) Springer-Verlag Berlin/Heidelberg 2005

\begin{abstract}
The objective of this study was to compare pain status after microlaparoscopic tubal sterilization under local anesthesia with mild sedation and after conventional laparoscopic tubal sterilization under general anesthesia. Between March 2003 and January 2004, 100 women undergoing laparoscopic tubal sterilization were equally and prospectively divided into two groups: microlaparoscopy (Group I) and conventional laparoscopy (Group II). For microlaparoscopic tubal sterilization a micro-telescope of $1.7 \mathrm{~mm}$ was used. Postoperative pain level was evaluated with the use of the visual analog scale (VAS) with scores ranging from 1 to 10. The groups were comparable in age, body mass index (BMI), and educational status. Group I had significantly lower VAS pain scores at 30-min ( $p=0.024), 1-\mathrm{h}(p=0.038)$, and 2-h $(p=0.016)$ intervals, although the 24-h $(p=0.655)$ and 48-h ( $p=0.988)$ scores of the two groups were similar. While none of the patients in Group I needed additional postoperative analgesic drugs, $12 \%$ of the patients in Group II required additional analgesia. There were no operative complications in either of the groups, and none of the patients required conversion from the microlaparoscopic technique to a traditional method. In conclusion, our data suggest that for women needing surgical sterilization, microlaparoscopy has the advantage of a lower postoperative discomfort rate with regard to VAS pain scores, especially within the first $2 \mathrm{~h}$.
\end{abstract}

Keywords Visual analog scale Pain score · Tubal sterilization · Laparoscopy

M. Polat $\cdot$ Y. Yildirim $(\bowtie) \cdot$ A. S. Onoglu

Department of Obstetrics and Gynecology,

SSK (Social Security Agency)

Aegean Obstetrics and Gynecology Teaching Hospital,

Izmir, Turkey

e-mail: ykuzeyli@mynet.com

\section{Introduction}

Tubal sterilization is an effective contraceptive method for women, with a Pearl index of 0.18 [1-3]. In the United States, approximately $18 \%$ of all women between the ages of 15 and 40 have preferred tubal sterilization for contraception $[4,5]$. In Turkey, this rate is $4.2 \%$ [6].

Microlaparoscopy has been evaluated for minimally invasive laparoscopy using minimal anaesthesia or analgesia since 1993 [7-9]. This method has been performed for many pelvic conditions and for tubal sterilization [10-12]. The cost of microlaparoscopic tubal sterilization is $70 \%$ lower compared with conventional laparoscopic tubal sterilization [7, 13]. It is estimated that if $50 \%$ of the 200,000 laparoscopic sterilizations performed in the US each year were carried out using microlaparoscopy instead of traditional laparoscopy, $\$ 55$ billion would be yielded as a profit each year [14].

Pain research has tried to explore the neuronal and molecular bases of the pain system during several clinically relevant forms of pain such as cancer pain, neuropathic pain, and postoperative pain [15]. Postoperative pain is a major symptom after surgery. Potential interactions between the nociceptive, motor, and autonomic systems are considered for this condition [16]. Neuropeptides and postoperative pain are also discussed in relation to somatostatin, tachykinin, cholecystokinin, and their antagonists [17]. The discovery of the endogen opioid system and peripheral opioid receptors, noradrenergic and serotoninergic antinociceptive systems, and muscarinic and nicotinic receptors in nociception have allowed for optimization of pain treatment through the use of new drugs and therapies [18]. Recent research has not only developed pre-emptive, multimodal, and mechanism-based therapies for pain relief, but has also tried to determine and extend more less invasive techniques to many forms of surgical interventions.

The objective of this study was to compare pain status after microlaparoscopic tubal sterilization under local anesthesia with mild sedation and after conventional laparoscopic tubal sterilization under general anesthesia. 


\section{Material and methods}

Patients

One hundred women who applied to SSK (Social Security Agency) Aegean Obstetrics and Gynecology Teaching Hospital, Departments of Family Planning and Gynecology for tubal sterilization between March 2003 and January 2004 were equally divided into two groups. In the Group I a microlaparoscopic tubal sterilization procedure under local anesthesia was carried out and in Group II conventional laparoscopic tubal sterilization under general anesthesia was applied.

The study was approved by the Institutional Review Board (IRB) of our hospital. Informed consent was obtained from each patient after the purpose and nature of the study had been fully explained. The study was also conducted in accordance with the Helsinki Declaration of 1975 on human experimentation.

Cases of major systemic disease, menstrual irregularity and dysmenorrhea, obesity (BMI $>28$ ), and patients with a history of major abdominopelvic surgery (except cesarean section) were excluded from the study.

Naproxen sodium (500 mg orally) was started at 15 th minute after the operation and it was continued at one dose every $8 \mathrm{~h}$. All patients were discharged by the end of the operation day and controlled in policlinics $24 \mathrm{~h}, 48 \mathrm{~h}$, and 1 week after the operation.

Pain scores were estimated $30 \mathrm{~min}, 1 \mathrm{~h}, 2 \mathrm{~h}, 24 \mathrm{~h}$, and $48 \mathrm{~h}$ after surgery. Time of operation, complications during or after operation, period of hospitalization, and additional analgesic requirements were also recorded for each patient.

Operative technique

The patients were placed in the lithotomy position for microlaparoscopic tubal sterilization. Midazolam $(0.1 \mathrm{mg} /$ $\mathrm{kg}$ intravenously) was administered for sedation and $5 \mathrm{ml}$ of $5 \%$ bupivacaine was administered to the periumbilical, right and left suprapubic areas for local anesthesia. The abdomen was entered through the umbilicus using an office laparoscopic Verres needle and 1.5-2 1 carbon dioxide $\left(\mathrm{CO}_{2}\right)$ was insufflated. After the pneumoperitoneum was reached, a $1.7-\mathrm{mm}$ micro-telescope was placed into the abdominal cavity. After the ful visualization of the peritoneal cavity was realized, an area $2-3 \mathrm{~cm}$ distally of the fallopian tubes from the cornual area was coagulated with bipolar cautery and cut. After hemorrhage control, $\mathrm{CO}_{2}$ was evacuated and the procedure was completed.

For conventional laparoscopic tubal sterilization, a 10$\mathrm{mm}$ optic tool and general anesthesia were used instead.

\section{Pain scores}

To calculate the severity of postoperative pain, the visual analog scale (VAS) was used [19]. This scale includes a total of 11 points $(0-10)$ from left to right. Zero denotes absence of pain and 10 points conveys the highest degree of pain.
Table 1 Demographic characteristics of the patients. BMI body mass index

\begin{tabular}{llll}
\hline & $\begin{array}{l}\text { Group I } \\
(N=50)\end{array}$ & $\begin{array}{l}\text { Group II } \\
(N=50)\end{array}$ & $\begin{array}{l}p \\
\text { Value }\end{array}$ \\
\hline Age (years, mean $\pm \mathrm{SD})$ & $36.4 \pm 4.7$ & $36.9 \pm 4.5$ & 1.466 \\
Body weight $(\mathrm{kg}$, & $66.7 \pm 11.3$ & $67.7 \pm 12.6$ & 0.998 \\
$\quad$ mean $\pm \mathrm{SD})$ & & & \\
BMI $\left(\mathrm{kg} / \mathrm{m}^{2}\right.$, mean $\left.\pm \mathrm{SD}\right)$ & $25.3 \pm 3.2$ & $25.5 \pm 3.7$ & 1.143 \\
Educational status & & & 0.852 \\
Primary School $(n, \%)$ & $42(84 \%)$ & $43(86 \%)$ & \\
Secondary school $(n, \%)$ & $2(4 \%)$ & $3(6 \%)$ & \\
High school $(n, \%)$ & $6(12 \%)$ & $4(8 \%)$ & \\
\hline
\end{tabular}

Statistical analysis

All data management and statistical analyses were carried out using the pocket version of the Statistical Program for Social Sciences (SPSS) version 11.0 for Windows. Demographic characteristics and postoperative recovery times of the patients in the groups were compared using the Chisquared test or the Student's $t$ test. To compare VAS pain scores the Mann Whitney $U$ test was used. Two-tailed $p<0.05$ was accepted as statistical significance.

\section{Results}

The two groups were similar with respect to demographic data. Table 1 shows the demographic characteristics of the patients.

The mean operating time in Groups I and II was $27.1 \pm 4.3 \mathrm{~min}$ and $25.9 \pm 3.8 \mathrm{~min}$ II respectively $(p=0.966)$. The mean recovery time in Groups I and II was $2.2 \pm 0.3 \mathrm{~h}$ and $3.8 \pm 0.5 \mathrm{~h}$ respectively $(p=0.014)$. No major or minor complications were observed in either of the groups.

Taking into consideration VAS pain scores, 30-min ( $p=0.024), 1-\mathrm{h}(p=0.038)$, and 2-h $(p=0.016)$ postoperative scores were significantly lower in the microlaparoscopy group. Contrary to this, there were no significant differences between the two groups with respect to 24-h

Table 2 Visual analogue scale (VAS) pain scores of the groups

\begin{tabular}{|c|c|c|c|}
\hline & Group I $(N=50)$ & Group II $(N=50)$ & $p$ value \\
\hline $\begin{array}{l}\text { 30th minute VAS score } \\
(\text { mean } \pm \mathrm{SD})\end{array}$ & $5.85 \pm 0.48$ & $7.64 \pm 0.56$ & 0.024 \\
\hline $\begin{array}{l}\text { First hour VAS score } \\
\qquad(\text { mean } \pm \mathrm{SD})\end{array}$ & $4.24 \pm 0.31$ & $5.75 \pm 0.44$ & 0.038 \\
\hline $\begin{array}{l}\text { 2nd hour VAS score } \\
\qquad(\text { mean } \pm \mathrm{SD})\end{array}$ & $3.34 \pm 0.26$ & $4.99 \pm 0.33$ & 0.016 \\
\hline $\begin{array}{l}\text { 24th hour VAS score } \\
\qquad(\text { mean } \pm \mathrm{SD})\end{array}$ & $1.76 \pm 0.17$ & $1.65 \pm 0.16$ & 0.655 \\
\hline $\begin{array}{l}\text { 48th hour VAS score } \\
(\text { mean } \pm \text { SD) }\end{array}$ & $1.11 \pm 0.03$ & $1.08 \pm 0.02$ & 0.988 \\
\hline
\end{tabular}


$(p=0.655)$ and 48 -h $(p=0.988)$ VAS pain scores. The VAS pain scores are shown in Table 2.

Within the first $2 \mathrm{~h}$, while six patients in Group II required additional analgesia (5 patients with additional naproxen doses and 1 patient with $50 \mathrm{mg}$ meperidine intramuscularly), no patients in Group I needed additional analgesia apart from our standard regimen.

\section{Discussion}

Two previous controlled clinical studies reported that patients who had microlaparoscopic tubal sterilization had lower postoperative VAS pain scores than those who had conventional laparoscopic tubal sterilization $[12,20]$. Our study showed that VAS pain scores in the first two hours were significantly less in the microlaparoscopy group than those in the conventional group. Additionally, $12 \%$ of the patients in Group II required further analgesia. However, these differences were not observed between the 24-h and 48-h scores. The mean operating and recovery times were also significantly less in the microlaparoscopy group than those in the traditional laparoscopy group. These data show that microlaparoscopy has better postoperative comfort than the conventional technique, especially in the early postoperative period.

It was also reported that postoperative intraperitoneal lidocaine administration and bupivacaine infiltration of the trocar sites were beneficial for patients undergoing microlaparoscopy [21, 22]. However, we administered neither lidocaine instillation into the peritoneal cavity nor bupivacaine infiltration of the trocar sites.

Some studies have discussed that local anesthesia is an affordable alternative to general anesthesia for microlaparoscopy $[9,23]$. Zupi et al. reported that in women receiving local anesthesia, only $5.5 \%$ required general anesthesia to complete the procedure. Their groups also had no statistically significant differences in pain levels $1 \mathrm{~h}$ after the procedure, in the number of complications, and in pelvic pathology. Their patients who had local anesthesia also required a smaller volume of $\mathrm{CO}_{2}$ and their hospitalization was significantly shorter. However, in $15 \%$ of these women pelvic visualization was incomplete, compared with $7.2 \%$ in the general anesthesia group [9]. Mazdisnian et al. reported that office microlaparoscopy for female sterilization under local anesthesia was completed in $93 \%$ of patients [24]. We performed all procedures under local anesthesia with conscious sedation and we did not detect any cases of incomplete visualization or requiring conversion from the microlaparoscopic technique to a traditional method.

In conclusion, our data suggest that for women needing surgical sterilization, microlaparoscopy has the advantage of a lower postoperative discomfort rate with regard to VAS pain scores, especially within the first $2 \mathrm{~h}$.

\section{References}

1. Pati S, Cullins V (2000) Female sterilization. Evidence. Obstet Gynecol Clin North Am 27:859-899
2. Wilson EW (1995) The evolution of methods for female sterilization. Int J Gynecol Obstet 51:3-13

3. Wilson EW (1996) Sterilization. Baillieres Clin Obstet Gynaecol 10:103-119

4. Westhoff C, Davis A (2000) Tubal sterilization: focus on the U.S. experience. Fertil Steril 73:913-922

5. MacKay AP, Kieke BA, Konin LM, Beattie K (2001) Tubal sterilization in the United States, 1994-1996. Fam Plann Perspect 33:161-165

6. Ozalp S, Yalcın OT, Hassa H, Erbay B, Dalan N (1999) Factors affecting the contraceptive choice in a developing country. Int J Gynaecol Obstet 65:53-57

7. Poindexter AN III, Abdul-Malak M, Fast JE (1990) Laparoscopic tubal sterilization under local anesthesia. Obstet Gynecol 75:5-8

8. Risquez F, Pennehouat G, Fernandez R, Confino E, Rodriguez O (1993) Microlaparoscopy: a preliminary report. Hum Reprod 8:1701-1702

9. Zupi E, Marconi D, Sbracia M, Solima E, Zullo F, Dauri M, Romanini C (2000) Is local anesthesia an affordable alternative to general anesthesia for minilaparoscopy? J Am Assoc Gynecol Laparosc 7:111-114

10. Almeida OD Jr, Val-Gallas JM (1998) Office microlaparoscopy under local anesthesia in the diagnosis and treatment of chronic pelvic pain. J Am Assoc Gynecol Laparosc 5:407-410

11. Pellicano M, Zullo F, Di Carlo C, Zupi E, Nappi C (1998) Postoperative pain control after microlaparoscopy in patients with infertility: a prospective randomized study. Fertil Steril 70:289-292

12. Tiras MB, Gokce O, Noyan V, Zeyneloglu HB, Guner H, Yildirim M, Risquez F (2001) Comparison of microlaparoscopy and conventional laparoscopy for tubal sterilization under local anesthesia with mild sedation. J Am Assoc Gynecol Laparosc 8:385-388

13. Palter SF, Duleba A, Zreik T, DiStasio C, Mandel T, Guarnaccia $M$ et al (1996) Office microlaparoscopy under local anesthesia. J Am Assoc Gynecol Laparosc 3:38

14. Lipscomb GH, Dell JR, Ling FW, Spellman JR (1996) A comparison of the cost of local versus general anesthesia for laparoscopic sterilization in an operating room setting. J Am Assoc Gynecol Laparosc 3:277-281

15. Schaible HG, Richter F (2004) Pathophysiology of pain. Langenbecks Arch Surg 389:237-243

16. Wright A (1999) Recent concepts in the neurophysiology of pain. Man Ther 4:196-202

17. Duggan AW (1992) Neuropharmacology of pain. Curr Opin Neurol Neurosurg 5:503-507

18. Wordliczek J, Dobrogowski J (2000) Pathophysiology of postoperative pain. Przegl Lek 57:201-210

19. DeLoach LJ, Higgins MS, Caplan AB, Stiff JL (1998) The visual analog scale in the immediate postoperative period: intrasubject variability and correlation with a numeric scale. Anesth Analg 86:102-106

20. Garcia FA, Steinmetz I, Barker B, Huggins GR (2000) Economic and clinical outcomes of microlaparoscopic and standard laparoscopic sterilization. A comparison. J Reprod Med 45:372-376

21. Pellicano M, Zullo F, Di Carlo C, Zupi E, Nappi C (1998) Postoperative pain control after microlaparoscopy in patients with infertility: a prospective randomized study. Fertil Steril 70:289-292

22. Zullo F, Pellicano M, Cappiello F, Zupi E, Marconi D, Nappi C (1998) Pain control after microlaparoscopy. J Am Assoc Gynecol Laparosc 5:161-163

23. DeQuattro N, Hibbert M, Buller J, Larsen F, Russell S, Poore S et al (1998) Microlaparoscopic tubal ligation under local anesthesia. J Am Assoc Gynecol Laparosc 5:55-58

24. Mazdisnian F, Palmieri A, Hakakha B, Hakakha M, Cambridge C, Lauria B (2002) Office microlaparoscopy for female sterilization under local anesthesia. A cost and clinical analysis. J Reprod Med 47:97-100 